\title{
PENDIDIKAN KESEHATAN MENINGKATKAN PRAKTIK PERAWATAN METODE KANGURU (PMK) PADA IBU NIFAS DENGAN BAYI BERAT LAHIR RENDAH
}

\author{
Puji Hastuti*) ; Septerina Purwandani W ; Riza Amalia ; Akbar Yuli Setianto \\ Jurusan Kebidanan Purwokerto; Poltekkes Kemenkes Semarang \\ Jl. Tirto Agung; Pedalangan; Banyumanik; Semarang
}

\begin{abstract}
Abstrak
Salah satu cara yang digunakan untuk mengurangi kesakitan dan kematian yang disebabkan oleh BBLR adalah dengan menggunakan perawatan metode kanguru. Metode ini merupakan salah satu teknologi tepat guna yang sederhana, murah dan dapat digunakan apabila fasilitas untuk perawatan BBLR sangat terbatas. Tujuan penelitian menganalisa efektifitas Praktik Perawatan Metode Kanguru (PMK) pada Ibu Nifas Dengan Bayi Berat Lahir Rendah. Penelitian berjenis rancangan experiment semu (Quasi Experiment), dengan menggunakan design "Pretest-postest Control Group Design". Data yang dikumpulkan adalah data primer yang meliputi praktik perawatan metode kanguru pada ibu nifas yang melahirkan bayi dengan berat lahir rendah dan dirawat di RSUD Prof Dr Margono Soekarjo Purwokerto menggunakan teknik accidental sampling. Pendidikan kesehatan efektif meningkatkan praktik perawatan metode kanguru dengan Asymp. Sig 0,001 $(\mathrm{P}<0,05)$, Saran diberikan kepada petugas kesehatan senantiasa meningkatkan dukungan terhadap keluarga untuk menerapkan perawatan metode kanguru dengan memberikan pendidikan kesehatan dan membantu dalam pelaksanaannya.
\end{abstract}

Kata kunci: Skrining ; Pendampingan ; Penyakit Tidak Menular

\begin{abstract}
[IMPROVING HEALTH CARE PRACTICE EDUCATION METHOD KANGURU (PMK) POSTPARTUM WOMEN WITH LOW BIRTH WEIGHT BABIES] One of the ways used to reduce morbidity and mortality caused by low birth weight is to use kangaroo care method. This method is one of the appropriate technology is simple, inexpensive and can be used if the facility for the care of LBW very limited. But among the people of Indonesia, the kangaroo method is not widely known, but this method is quite effective and easy to do. The research objective to analyze the effectiveness of Kangaroo Care Practice (PMK) On Postpartum Mothers With Low Birth Weight Babies. Research manifold design experimental quasi (quasi-experiment), using design "pretest-posttest control group design". Data were collected primary data including kangaroo care practices method in postpartum mothers who give birth to babies with low birth weight and being treated in hospitals Prof. Dr. Margono Soekarjo Purwokerto using accidental sampling technique. Health education effectively improve care practices with Asymp kangaroo method. Sig 0.001 (P $<0.05)$ Advice given to health care workers continue to increase support for the family to adopt kangaroo care method to provide health education and assist in its implementation.
\end{abstract}

Keywords: Health Education ; Nursing Kangaroo

\section{Pendahuluan}

Bayi dengan berat lahir rendah merupakan penyumbang tertinggi angka kematian neonatal (AKN). Dari sekitar 4 juta kematian neonatal,

\footnotetext{
*) Puji Hastuti

E-mail: pujih75@gmail.com
}

prematur dan BBLR menyumbang lebih dari seperlima kasus, dan Indonesia terdaftar sebagai negara di urutan ke-8 berdasarkan jumlah kematian neonatal per tahun menurut data WHO.

Salah satu cara yang digunakan untuk mengurangi kesakitan dan kematian yang 
disebabkan oleh BBLR adalah dengan menggunakan perawatan metode kanguru. Metode ini merupakan salah satu teknologi tepat guna yang sederhana, murah dan dapat digunakan apabila fasilitas untuk perawatan BBLR sangat terbatas. Namun di kalangan masyarakat Indonesia, metode kanguru belum banyak dikenal, padahal metode ini cukup efektif dan mudah dilakukan. Menurut Penelitian Sulistyowati, 2015 menyebutkan dalam pelaksanaan tindakan Perawatan Metode Kanguru di Rumah Sakit Margono Soekarjo Purwokerto terdapat beberapa hambatan antara lain rendahnya kemauan pasien untuk menerapkan metode kanguru.

Perawatan Metode Kanguru (PMK) bermanfaat dalam menurunkan secara bermakna jumlah neonatus atau bayi baru lahir yang meninggal, menghindari bayi berat lahir rendah dari kedinginan (hipotermia), menstabilkan bayi, mengurangi terjadinya infeksi, meningkatkan pertumbuhan dan perkembangan bayi, meningkatkan pemberian ASI, dan meningkatkan ikatan (bonding) antara ibu dan bayi.

Guna meningkatkan pemahaman masyarakat terhadap metode perawatan kanguru perlu dikenalkan lebih lanjut. Salah satu upaya yang dapat dilakukan adalah pendidikan kesehatan. Tujuan penelitian adalah mengidentifikasi Praktik Tentang Perawatan Metode Kanguru (PMK) Pada Ibu Nifas Dengan Bayi Berat Lahir Rendah sebelum dan sesudah diberi pendidikan kesehatan serta menganalisa efektifitas Praktik Tentang Perawatan Metode Kanguru (PMK) Pada Ibu Nifas Dengan Bayi Berat Lahir Rendah.

\section{Metode}

Penelitian berjenis rancangan experiment semu (Quasi Experiment), dengan menggunakan design " Pretest-postest Control Group Design". Data yang dikumpulkan adalah data primer yang meliputi praktik perawatan metode kanguru pada ibu nifas yang melahirkan bayi dengan berat lahir rendah dan dirawat di RSUD Prof Dr Margono Soekarjo Purwokerto menggunakan teknik accidental sampling dengan responden sejumlah 15 pada kelompok perlakuan dan 15 pada kelompok kontrol.

Dalam penelitian ini observasi dilakukan sebanyak dua kali pada kelompok perlakuan dan kelompok kontrol. Pada kelompok perlakuan yaitu sebelum eksperimen (O1) disebut pre test dan observasi sesudah eksperimen (O2) disebut post test. Perbedaan O1 dan O2 diasumsikan merupakan efek dari perlakuan. Pada kelompok kontrol yaitu observasi pertama (O3) disebut pre test dan observasi kedua (O4) disebut post test. Penelitian ini menggunakan uji beda yang sebelumnya dilakukan uji normalitas data dengan Shapiro-Wilk.

Untuk menguji perbedaan praktik sebelum dan sesudah perlakuan, maka perhitungan statistik menggunakan uji beda dependen (paired t-test), dan karena data tidak berdistribusi normal maka menggunakan uji Wilcoxon.

\section{Hasil dan Pembahasan}

Hasil penelitian menunjukkan pada kelompok perlakuan penilaian pertama lulus sebesar 33\% dan penilaian kedua kelulusan meningkat menjadi $93 \%$, dan yang tidak lulus pada penilaian pertama sebesar $67 \%$ menurun pada penilaian kedua menjadi $7 \%$. Pada kelompok kontrol penilaian pertama lulus sebesar $40 \%$ dan penilaian kedua meningkat menjadi $93 \%$ dan yang tidak lulus pada penilaian pertama sebesar $60 \%$ menurun pada penilaian kedua menjadi $7 \%$.

Hasil analisis Wilcoxon Match Paired Test didapatkan hasil Asymp. Sig 0,001 $(\mathrm{P}<0,05)$ maka Ha diterima dan Ho di tolak. Hal tersebut menunjukkan bahwa ada perbedaan Praktik Perawatan Metode Kanguru sebelum diberikan pendidikan kesehatan dan sesudah diberikan pendidikan kesehatan pada Ibu Nifas Dengan Bayi Berat Lahir Rendah.

Perawatan Metode Kanguru (PMK) merupakan perawatan untuk bayi berat lahir rendah atau lahiran prematur dengan melakukan kontak langsung antara kulit bayi dengan kulit ibu atau skin-to-skin contact, dimana ibu menggunakan suhu tubuhnya untuk menghangatkan bayi. Metode ini meniru binatang berkantung kanguru yang bayinya lahir memang sangat prematur, dan setelah lahir disimpan di kantung perut ibunya untuk mencegah kedinginan sekaligus mendapatkan makanan berupa air susu induknya.

Salah satu cara yang digunakan untuk mengurangi kesakitan dan kematian yang disebabkan oleh BBLR adalah dengan menggunakan perawatan metode kanguru. Penelitian memperlihatkan PMK bermanfaat dalam menurunkan secara bermakna jumlah neonatus atau bayi baru lahir yang meninggal, menghindari bayi berat lahir rendah dari kedinginan (hipotermia), menstabilkan bayi, mengurangi terjadinya infeksi, meningkatkan pertumbuhan dan perkembangan bayi, 
meningkatkan pemberian ASI, dan meningkatkan ikatan (bonding) antara ibu dan bayi. Beberapa penelitian tersebut antara lain .

Wahyuni, Sri (2010) Pengaruh Perawatan Bayi Lekat Terhadap Peningkatan Berat Badan Pada Bayi Dengan Berat Badan Lahir Rendah Di RS PKU Muhammadiyah Surakarta. Hasil pengujian Anova menunjukkan F hitung sebesar 50,40 dengan p-value 0,000, sehingga Ho ditolak. Kesimpulan penelitian menunjukkan: (1) terdapat pengaruh perawatan bayi lekat terhadap peningkatan berat badan pada bayi dengan berat badan lahir rendah di RS PKU Muhammadiyah Surakarta, dan (2) perawatan bayi lekat yang paling efektif dalam meningkatkan berat badan pada bayi dengan berat badan lahir rendah adalah tiap 6 jam sekali.

Zakiah, Norhajati Bt. Zulbachri Noor Erni Setiawati melakukan penelitian Efektifitas Peningkatan Suhu Tubuh Pada Perawatan Metode Kangguru Dengan Perawatan Inkubator Di BLUD Rs H. Boejasin Pelaihari Tanah Laut Tahun 2013 menunjukkan bahwa dari rerata peningkatan suhu tubuh bayi pada penerapan perawatan PMK yaitu 0,2920 (SD=0,08124). Pada penerapan perawatan inkubator didapatkan rerata peningkatan suhu tubuh 0,1320 $(\mathrm{SD}=0,14353)$. Penerapan PMK lebih efektif dibandingkan dengan perawatan inkubator dalam meningkatkan suhu tubuh bayi BBLR.

Penelitian yang dilakukan oleh Qori'Ila Saidah, Yeni Rustina, Nani Nurhaeni dengan judul Penurunan Kecemasan Ibu dan Perbaikan Status Bangun-Tidur BBLR melalui Perawatan Metode Kanguru menunjukkan ada perbedaan bermakna ( $p=0,000 ; a=0,05)$. PMK mempunyai pengaruh signifikan terhadap perubahan kecemasan ibu dan status bangun-tidur BBLR.

Silvia : 2014 melakukan penelitian tentang pengaruh perawatan metode kanguru terhadap perubahan berat badan bayi lahir rendah di RSUD Dr. Achmad Moechtar Bukittinggi mendapatkan hasil rata-rata berat badan bayi sebelum diberikan perawatan metode kanguru adalah 1738,60 gram dan setelah dilakukan perawatan metode kanguru meningkat 1766,9 gram dengan peningkatan 28,3 gram dimana $(p=$ $0,000 ; a=0,05)$.

Perawatan Metode Kanguru ini merupakan salah satu teknologi tepat guna yang sederhana, murah dan dapat digunakan apabila fasilitas untuk perawatan BBLR sangat terbatas. Namun di kalangan masyarakat Indonesia, metode kanguru belum banyak dikenal, padahal metode ini cukup efektif dan mudah dilakukan. Guna meningkatkan pemahaman masyarakat terhadap metode perawatan kanguru perlu dikenalkan lebih lanjut. Penelitian Sulistyowati, 2015 menyebutkan dalam pelaksanaan tindakan Perawatan Metode Kanguru di Rumah Sakit Margono Soekarjo Purwokerto terdapat beberapa hambatan antara lain rendahnya kemauan pasien untuk menerapkan metode kanguru. Hal tersebut sejalan dengan penelitian Magdalena : 2012 dengan judul pengetahuan ibu tentang penatalaksanaan perawatan bayi BBLR di rumah di RSKIA Kota Bandung yang mendapatkan hasil pengetahuan ibu dalam penatalaksanaan perawatan mempertahankan suhu dan kehangatan bayi pada kategori kurang, penatalaksanaan pemberian ASI dalam kategori cukup dan pengetahuan ibu dalam pencegahan terjadinya infeksi pada BBLR pada kategori kurang.

Kriteria untuk mengikuti program perawatan bayi dengan metode kanguru sebagaimana ditetapkan oleh ISS World Laboratory kangaroo mother program yaitu : berat badan < 2000 gram, tidak ada kelainan patologis yang menyertai, reflek isap baik, koordinasi reflek isap dan menelan baik, mempunyai orang tua yang menyetujui metode kanguru, dan mematuhi jadual pertemuan.

Tabel 1. Distribusi frekuensi responden berdasarkan Praktik Tentang Perawatan Metode Kanguru (PMK) Pada Ibu Nifas Dengan Bayi Berat Lahir Rendah Pada Kelompok Perlakuan dan Kelompok Kontrol

\begin{tabular}{|c|c|c|c|c|c|c|c|c|}
\hline \multirow[t]{3}{*}{ Praktik PMK } & \multicolumn{4}{|c|}{ Kelompok Perlakuan } & \multicolumn{4}{|c|}{ Kelompok Kontrol } \\
\hline & \multicolumn{2}{|c|}{ O1 } & \multicolumn{2}{|c|}{$\mathrm{O} 2$} & \multicolumn{2}{|c|}{$\mathrm{O} 3$} & \multicolumn{2}{|c|}{$\mathrm{O} 4$} \\
\hline & $\mathrm{F}$ & $\%$ & $\mathrm{~F}$ & $\%$ & $\mathrm{~F}$ & $\%$ & $\mathrm{~F}$ & $\%$ \\
\hline Lulus & 5 & 33 & 14 & 93 & 6 & 40 & 14 & 93 \\
\hline Tidak Lulus & 10 & 67 & 1 & 7 & 9 & 60 & 1 & 7 \\
\hline Total & 15 & 100 & 15 & 100 & 15 & 100 & 15 & 100 \\
\hline
\end{tabular}

Signifikan $(\mathrm{p}<0,05), p=0,001$ 
memiliki catatan medik yang lengkap serta memperoleh informed consent dari orang tua. Dalam pelaksanaannya perlu diperhatikan ibu, bayi, posisi bayi, observasi bayi, cara pemberian ASI, serta kebersihan ibu dan bayi. (Suradi:2000). Selain itu diperlukan juga dukungan tenaga kesehatan yang baik dalam pelaksanaan perawatan metode kanguru sebagaimana penelitian Puspitaningsih : 2011 bahwa tenaga kesehatan perlu memiliki sikap yang positif dan pernah melaksanakan metode kanguru.

Salah satu upaya yang dapat dilakukan dalam meningkatkan praktik Prawatan Metode kanguru adalah pendidikan kesehatan. Pendidikan kesehatan adalah kegiatan pendidikan yang dilakukan dengan cara menyebarkan pesan, menanamkan keyakinan, sehingga masyarakat tidak saja sadar, tahu, dan mengerti, tetapi juga mau dan bisa melakukan suatu anjuran yang ada hubungannya dengan kesehatan (Effendy, 2008).

Hasil penelitian tentang Praktik Perawatan Metode Kanguru Pada Ibu Nifas Dengan Bayi Berat Lahir Rendah sebagaimana terlihat pada tabel 1.

Dari table 1. hasil penelitian menunjukkan pada kelompok perlakuan penilaian pertama lulus sebesar 33\% dan penilaian kedua kelulusan meningkat menjadi $93 \%$, dan yang tidak lulus pada penilaian pertama sebesar $67 \%$ menurun pada penilaian kedua menjadi $7 \%$. Pada kelompok kontrol penilaian pertama lulus sebesar $40 \%$ dan penilaian kedua meningkat menjadi $93 \%$ dan yang tidak lulus pada penilaian pertama sebesar $60 \%$ menurun pada penilaian kedua menjadi $7 \%$.

Praktik Perawatan Metode Kanguru yang dilakukan oleh responden mengalami peningkatan kelulusan dari sebelum diberi pendidikan kesehatan dan sesudah pendidikan kesehatan. Pada kelompok perlakuan dari kelulusan sejumlah $33 \%$ sebelum diberi pendidikan kesehatan menjadi $93 \%$ sesudah diberi pendidikan kesehatan. Hasil penelitian menunjukkan dari analisis Wilcoxon Match Paired Test didapatkan hasil Asymp. Sig 0,001 $(\mathrm{P}<0,05)$ maka Ha diterima dan Ho di tolak. Hal tersebut menunjukkan bahwa ada perbedaan Praktik Perawatan Metode Kanguru sebelum diberikan pendidikan kesehatan dan sesudah diberikan pendidikan kesehatan pada Ibu Nifas Dengan Bayi Berat Lahir Rendah, sehingga dapat ditarik kesimpulan bahwa pendidikan kesehatan efektif meningkatkan praktik perawatan metode kanguru.
Praktik yang berkaitan dengan pendidikan adalah praktek atau tindakan yang dilakukan oleh peserta didik sehubungan dengan materi yang diberikan. Praktik ini dapat terjadi melalui empat (4) tingkatan sebagai berikut pertama persepsi yaitu mengenal dan memilih berbagai obyek sehubungan dengan tindakan yang akan diambil. Tingkatan kedua adalah respon terpimpin dimana kita melakukan sesuatu sesuai dengan urutan yang benar dan sesuai dengan contoh. Tingkatan ketiga adalah mekanisme yang terjadi apabila seseorang telah dapat melakukan sesuatu dengan benar secara otomatis, atau sesuatu itu sudah merupakan kebiasaan. Tingkatan keempat adalah adopsi yaitu suatu praktik atau tindakan yang sudah berkembang dengan baik, artinya tindakan itu sudah dimodifikasi tanpa mengurangi kebenaran tindakan tersebut. (Wahit, 2006)

Pendidikan kesehatan adalah proses untuk meningkatkan kesehatannya. Selain itu, untuk mencapai derajat kesehatan yang sempurna, baik fisik mental dan sosial, maka masyarakat harus mampu mengenal dan mewujudkan apresiasinya, kebutuhannya dan mampu mengubah atau mengatasi lingkungannya (lingkungan fisik, sosial budaya, dan sebagainya). Agar bisa memberikan pendidikan kesehatan yang efektif perlu dilakukan dengan metode yang tepat dan alat bantu yang menarik. Metode pendidikan kesehatan dapat diberikan secara individu maupun kelompok sesuai dengan kebutuhan, situasi dan kondisi.

Adapun alat bantu atau alat peraga disusun berdasarkan prinsip bahwa pengetahuan yang ada pada setiap manusia diterima atau ditangkap melalui panca indra, sehingga pada prinsipnya adalah mengerahkan indra sebanyak mungkin kepada suatu obyek sehingga memudahkan pemahaman. Manfaat alat bantu kesehatan antara lain: menimbulkan minat sasaran pendidikan, mencapai sasaran yang lebih banyak, membantu dalam mengatasi banyak hambatan dalam pemahaman, merangsang sasaran pendidikan untuk meneruskan pesan-pesan yang diterima kepada orang lain, mempermudah penyampaian bahan pendidikan oleh para pendidik, mempermudah penerimaan informasi oleh sasaran pendidikan, mendorong keinginan orang untuk mengetahui, dan membantu menegakkan pengertian yang diperoleh.

\section{Simpulan dan Saran}


Praktik Tentang Perawatan Metode Kanguru (PMK) Pada Ibu Nifas Dengan Bayi Berat Lahir Rendah Sebelum Diberi Pendidikan Kesehatan menunjukkan hasil lulus 33\% dan tidak lulus $67 \%$ dan sesudah diberi Pendidikan Kesehatan menunjukkan hasil lulus 93\%, dan tidak lulus 7\%. Pendidikan kesehatan efektif meningkatkan praktik perawatan metode kanguru dengan Asymp. Sig 0,001 (P<0,05)

Rumah Sakit menyiapkan media yang efektif guna memberikan pendidikan kesehatan baik secara individu maupun kelompok kepada keluarga dengan bayi berat lahir rendah. Petugas kesehatan senantiasa meningkatkan dukungan terhadap keluarga untuk menerapkan perawatan metode kanguru dengan memberikan pendidikan kesehatan dan membantu dalam pelaksanaannya Ibu nifas dengan bayi berat lahir rendah hendaknya mempunyai sikap positif dengan menerapkan pendidikan kesehatan tentang perawatan metode kanguru yang telah diterimanya

\section{Ucapan Terima Kasih}

Terima kasih kepada Direktur Poltekkes Kemenkes Semarang, DIPA Poltekkes Kemenkes Semarang yang telah mendanai penelitian ini, Tim penyusun pengabmas dan semua pihak yang terlibat dalam penyusunan artikel penelitian ini.

\section{Daftar Pustaka}

Efendi, 1998. Dasar-Dasar Keperawatan -Kesehatan Masyarakat, Jakarta : EGC

Hidayat, Aziz Alimul.2007.Metode penelitian kebidanan dan teknik analisis data.Jakarta:Salemba Medika

Magdalena.2012.Pengetahuan Ibu Tentang Penatalaksanaan Perawatan Bayi Bblr Di Rumah di RSKIA Kota Bandung. Unpad : Bandung

Notoatmodjo, Soekijo, 2003.Pendidikan dan perilaku kesehatan.Jakarta:PT Rineka Cipta:
Pusdiklatnakes.2015.Buku ajar kesehatan ibu dan anak.Jakarta

Puspitaningsih, Nawang.2011. Gambaran Sikap Tenaga Kesehatan Dan Pelaksanaan Metode Kanguru Pada Bayi Berat Lahir Rendah Di Ruang Perionatalogi RSUD Dr Soeprapto Cepu Tahun 2011.FIK Unimus : Semarang

Qori' Ila Saidah, Yeni Rustina, Nani Nurhaeni. Penurunan Kecemasan Ibu dan Perbaikan Status Bangun-Tidur BBLR melalui Perawatan Metode Kanguru http://www.jki.ui.ac.id/index.php/jki/a rticle/view/309

Silvia.2014. Pengaruh Perawatan Metode Kanguru Terhadap Perubahan Berat Badan Bayi Lahir Rendah Di RSUD Dr. Achmad Moechtar Bukittinggi. Jurnal IPTEKS Terapan. Vol 9. i1(11-19). ISSN 1979-9292

Suradi, Rulina.2002.Metode Kanguru Sebagai Metode Pengganti Inkubator Untuk Bayi Dengan Berat lahir Rendah. Sari Pediatri Vol 1 No 2 Juni 2000:29-35.

Wahyuni, Sri (2010) Pengaruh Perawatan Bayi Lekat Terhadap Peningkatan Berat Badan Pada Bayi Dengan Berat Badan Lahir Rendah Di Rs Pku Muhammadiyah Surakarta. Skripsi Thesis, Universitas Muhammadiyah Surakarta. Http:/ / Eprints.Ums.Ac.Id/10474/

Zakiah, Norhajati Bt. Zulbachri Noor, Erni Setiawati (2013) Efektifitas Peningkatan Suhu Tubuh Pada Perawatan Metode Kangguru Dengan Perawatan Inkubator Di Blud Rs H. Boejasin Pelaihari Tanah Laut Tahun 2013

http://www.idai.or.id/artikel/klinik/asi/pera watan-metode-kanguru-pmk-meningkatk an-pemberian-asi 